\title{
Pengentasan Kemiskinan melalui Social Entrepreneurship Berbasis Industri Kreatif dan Desa Wisata di Dusun Munti Gunung, Desa Tianyar Barat
}

\author{
Ni Made Andriani ${ }^{1}$, I Made Yoga Suandita ${ }^{2}$, Ni Made Arini ${ }^{3}$, Ni Luh Pegy Teristonia ${ }^{4}$, I \\ Wayan Widiana ${ }^{5 *}$ \\ 1,2,3,4,5 Program Studi Pendidikan Guru Sekolah Dasar, Universitas Pendidikan Ganesha, Singaraja, Indonesia \\ *Corresponding author: wayanwidiana85@undiksha.ac.id
}

\begin{abstract}
Abstrak
Dusun Munti Gunung menyuguhkan kombinasi pemandangan yang sangat indah. Keindahan alam yang memukau membuat daerah ini berpotensi untuk dijadikan tempat wisata outbound, hiking, dan camping. Akan tetapi, kekayaan alam Dusun Munti Gunung tersebut sangat berbanding terbalik dengan keadaan sosial ekonomi masyarakat setempat. Hal ini juga sebanding dengan industri-industri kreatif yang telah ada di Munti Gunung juga belum mampu memberikan dampak terhadap peningkatan ekonomi. Pengabdian kepada masyarakat ini bertujuan untuk mengatasi permasalahan tersebut dengan pembentukan social entrepreneurship berbasis industri kreatif dan desa wisata di Dusun Munti Gunung, Desa Tianyar Barat. Kegiatan pengabdian ini dilaksanakan dengan bentuk kegiatannya menggunakan metode FGD, sosialisasi, serta pelatihan dan pendampingan. Kegiatan ini menyasar masyakarat Dusun Munti Gunung dan bermitra dengan pemerintah Desa Tianyar Barat. Kegiatan ini menghasilkan luaran berupa terbentuknya community social entrepreneurship berbasis industri kreatif dan desa wisata untuk mewadahi masyarakat miskin di Dusun Munti Gunung. Hasil pengabdian kepada masyarakat ini diharapkan dapat mengatasi segala permasalahan kemiskinan yang ada di Dusun Munti Gunung, Desa Tianyar Barat.
\end{abstract}

Kata Kunci: Social Entrepreneurship, Industri Kreatif, Desa Wisata

\section{Abstract}

Dusun Munti Gunung offers a very beautiful combination of views. The stunning natural beauty makes this area potential to be used as an outbound tourist spot, hiking, and camping. However, the natural wealth of Dusun Munti Gunung is very inversely proportional to the socio-economic conditions of the local community, this is also comparable to the existing creative industries in Dusun Munti Gunung which have not been able to have an impact on economic improvement. This community service aims to overcome these problems by establishing social entrepreneurship based on creative industries and tourism villages in Dusun Munti Gunung, Tianyar Barat Village. This service activity is carried out in the form of activities using the FGD method, socialization, as well as training and mentoring. This activity targets the Dusun Munti Gunung community and partners with the Tianyar Barat Village Government. This activity resulted in the formation of Community Social Entrepreneurship Based on Creative Industries and Tourism Villages to accommodate the poor in Dusun Munti Gunung. The results of this community service are expected to be able to overcome all the poverty problems that exist in Dusun Munti Gunung, Tianyar Barat Village.

Keywords: Social Entrepreneurship, Creative Industries, Tourism Village

\section{PENDAHULUAN}

Desa Tianyar Barat merupakan salah satu desa dari sembilan desa yang ada Kecamatan Kubu, Kabupaten Karangasem, Provinsi Bali. Batas wilayah Desa Tianyar Barat di sebelah timur Desa Tianyar Tengah, dis ebelah selatan Kabupaten Bangli, di sebelah barat Kabupaten Buleleng, dan di sebelah utara Laut Bali (Astuti et al., 2010; Citra \& Sarmita, 2019). Desa ini memiliki 14 dusun yakni Dusun Kerta Buana, Pakurenan, Semuh, Taman Sari, Labuan Sari, Tirta Sari, Buana Pule, Tegal Sari, Bengklok, Batu Minyeh, Munti

$\begin{array}{ll}\text { History: } & \\ \text { Received } & \text { : September 10, } 2021 \\ \text { Revised } & \text { : September 12, } 2021 \\ \text { Accepted } & \text { : November 03, } 2021 \\ \text { Published } & \text { : November } 25,2021\end{array}$


Gunung, Munti Gunung Tengah, Munti Gunung Kangin, dan Munti Gunung Kauh. Jumlah penduduk di Desa Tianyar Barat yakni sebanyak 13.105 jiwa. Desa Tianyar Barat memiliki berbagai sumber daya alam yang dimanfaatkan oleh masyarakat untuk memenuhi kebutuhan sehari-hari serta sebagai sumber mata pencaharian masyarakat. Di sepanjang jalan menuju Desa Tianyar Barat dari perbatasan antara kabupaten Buleleng dan kabupaten Karangasem terbentang luas perkebunan ental yang menjadi sumber penghasilan utama masyarakat. Desa Tianyar Barat sebenarnya memiliki beragam potensi yang dapat dimanfaatkan oleh masyarakat untuk meningkatkan perekonomiannya.

Dusun Munti Gunung terletak di daerah perbukitan. Puncak bukit Munti Gunung berseberangan langsung dengan Danau Batur di sebelah barat, sehingga menyuguhkan kombinasi pemandangan yang sangat indah (Astuti et al., 2010; Citra \& Sarmita, 2019). Keindahan alam yang memukau membuat daerah ini berpotensi untuk dijadikan tempat wisata outbound, hiking, dan camping. Keadaan alam di wilayah perbukitan Dusun Munti Gunung sangat menarik. Sepanjang mata memandang akan terlihat hamparan hutan dan perkebunan. Komoditas utama perkebunan di Dusun Munti Gunung antara lain pohon jambu mete, pohon ental, dan bunga rossela. Beberapa masyarakat setempat juga mengolah biji mete untuk dijual ke pengepul dengan kualitas baik. Getah bunga pohon ental diolah menjadi minuman tradisional tuak dan diolah juga menjadi gula aren. Daun ental juga dikelola menjadi berbagai kerajinan terutama yang berkaitan dengan sarana keagamaan yang disebut "jejahitan" dan juga dibuat sebagai kerajinan tangan berupa anyaman (Astuti et al., 2010; Citra \& Sarmita, 2019). Bunga rossela juga tumbuh dengan subur dan diolah menjadi teh yang berkhasiat. Selain itu, sebagian masyarakat Dusun Munti Gunung bekerja di bidang industri kreatif seperti batik dan hammock.

Akan tetapi, kekayaan alam Dusun Munti Gunung tersebut sangat berbanding terbalik dengan keadaan sosial ekonomi masyarakat setempat. Sejak tahun 1980-an dusun ini dikenal sebagai "Desa Gepeng". Sebagian besar masyarakat yang keadaan ekonominya berada pada garis kemiskinan "berprofesi" sebagai gelandangan dan pengemis di kota-kota besar di Bali. Gepeng merupakan salah satu masalah yang sangat sulit untuk ditanggulangi atau ditangani. Gelandangan adalah keadaan seseorang yang hidup dalam keadaan tidak sesuai dengan norma kehidupan yang layak dalam masyarakat setempat serta tidak memiliki tempat tinggal dan pekerjaan yang tetap di wilayah tertentu dan hidup mengembara di tempat umum. Sedangkan, pengemis adalah seseorang yang mendapatkan penghasilan dengan memintaminta di depan umum dengan berbagai cara dan alasan untuk mengharapkan belas kasihan dari orang lain. Aktivitas "menggepeng” bagi Dusun Munti Gunung, Desa Tianyar Barat, Kecamatan Kubu, Kabupaten Karangasem ini selalu diupayakan penanganannya oleh semua pihak, baik pemerintah, Prajuru Desa Adat, maupun oleh Lembaga Swadaya Masyarakat (LSM) yang punya perhatian besar terhadap masalah sosial (Yasa et al., 2014).Terlebih lagi di situasi pandemi Covid-19 ini, sebagian masyarakat menjadi pengangguran karena kurangnya lapangan pekerjaan, sehingga akan berpengaruh terhadap kemiskinan. Kemiskinan dapat diartikan sebagai ketidakmampuan seseorang dalam memenuhi kebutuhan konsumsi dasar dan meningkatkan kebutuhan konsumsi dasar dan kualitas hidupnya (Romi \& Umiyati, 2018; Rini \& Sugiharti, 2016). Kemiskinan merupakan salah satu masalah yang paling berat dalam pembangunan ekonomi yang dihadapi bangsa Indonesia serta tidak mudah keluar dari persoalan kemiskinan tersebut. Berbagai upaya telah dilakukan pemerintah, yaitu melalui program-program pengentasan kemiskinan seperti, Program Keluarga Harapan (PKH), Program Nasional Pemberdayaan Masyarakat (PNPM), dan sebagai-nya yang menghabiskan anggaran negara mencapai Rp.17 triliun (Rosyadi, 2017).

Berdasarkan permasalahan di atas, solusi yang ditawarkan adalah Program Holistik Pembinaan dan Pemberdayaan Desa atau biasa disebut PHP2D. Program ini dikembangkan langsung di bawah naungan Kementerian Pendidikan dan Kebudayaan dengan melaksanakan 
kegiatan pembinaan dan pemberdayaan masyarakat yang dilakukan oleh mahasiswa melalui Lembaga Eksekutif Mahasiswa dan Unit Kegiatan Mahasiswa. Program Holistik Pembinaan dan Pemberdayaan Desa (PHP2D) Tahun 2021 oleh Himpunan Mahasiswa Jurusan Pendidikan Dasar Universitas Pendidikan Ganesha dilaksanakan di Dusun Munti Gunung, Desa Tianyar Barat, Kecamatan Kubu, Karangasem. Program ini bertujuan yang pertama untuk meningkatkan kesadaran, mengubah pola pikir, dan menghapus mitos "kutukan kemiskinan" masyarakat Munti Gunung melalui pembentukan community social entrepreneurship, kedua meningkatkan pengetahuan masyarakat Munti Gunung dalam rangka untuk memberikan gambaran tentang potensi-potensi pekerjaan yang memungkinkan untuk dilakukan sesuai dengan potensi dan kondisi sosial, budaya, alam Munti Gunung, ketiga mengembangkan potensi kekayaan alam dan industri kreatif untuk meningkatkan perekonomian masyarakat serta untuk menunjang sektor pariwisata, keempat mengembangkan Munti Gunung's hiking track and camp area sebagai obyek wisata alternatif di Dusun Munti Gunung, kelima pengentasan kemiskian melalui social entrepreneurship berbasis industri kreatif dan desa wisata di Dusun Munti Gunung, Desa Tianyar Barat, Kecamatan Kubu, Karangasem, dan yang terakhir mengubah ikon Dusun Munti Gunung dari kampung pengemis menjadi kampung wisata.

\section{METODE}

Pendekatan metode penelitian yang digunakan adalah kualitatif. Pada proses kegiatannya menggunakan metode FGD, sosialisasi, serta pelatihan dan pendampingan. Focus group discussion lebih dikenal dengan singkatan FGD merupakan salah satu metode riset kualitatif yang paling terkenal dan diskusi terfokus dari suatu group untuk membahas suatu masalah tertentu dalam suasana informal dan santai (Swadayaningsih, 2020). Selain itu, FGD merupakan suatu proses pengumpulan data dan informasi kualitatif dengan cara sistematis mengenai suatu masalah yang dilakukan melalui diskusi kelompok (Fitriani \& Azhar, 2019; Waluyati, 2020). Adapun tujuan utama dari Focus Group Discussion (FGD) adalah agar memperoleh interaksi data dari hasil diskusi sekelompok partisipan dalam meningkatkan kedalaman informasi dari berbagai aspek fenomena kehidupan, sehingga fenomena tersebut dapat didefinisikan dan diberikan uraian penjelasannya. Selanjutnya, dilaksanakan sosialisasi kepada community social entrepreneurship dengan tim pelaksana. Sosialisasi adalah sebuah proses transfer atau pemberian kebiasaan, nilai, dan aturan dari satu generasi ke generasi lainnya dalam sebuah kelompok atau masyarakat, sehingga dapat memberikan pengalaman baru bagi kelompok atau masyarakat (Hamda, 2014; Herdiana, 2018).

Terakhir, dilakukannya pelatihan dan pendampingan untuk meningkatkan kemampuan masyarakat dalam mengaplikasikan pengetahuan dan keterampilan yang diperolehnya. Pelatihan adalah proses pembelajaran bagi masyarakat, sehingga dapat memberikan keterampilan baru dan memperbaiki kekurangan yang dialami (Putri \& Ratnasari, 2019). Pelatihan adalah seuatu proses pemberian pendidikan dalam jangka pendek yang menggunakan prosedur yang sistematik (terstruktur) dan terorganisasi yang dengan prosedur itu, masyarakat mendapatkan pengetahuan dan keterampilan teknis untuk mencapai tujuan tertentu (Hadinata, 2015). Pelatihan juga dapat diartikan sebagai proses pembelajaran yang lebih menekankan praktik daripada toeri yang dilakukan oleh individu atau kelompok dengan tujuan untuk meningkatkan kemampuan dalam satu atau beberapa jenis keterampilan tertentu (Santoso, n.d.). Pemberian pelatihan merupakan hal yang sangat penting karena pelatihan tidak hanya memanfaatkan tenaga kerja tetapi juga salah satu upaya untuk memajukan masyarakat dalam menjalankan tugasnya masing-masing (Muhlis et al., 2018). Sedangkan pendampingan adalah upaya atau cara yang dilakukan secara terus menerus dan sistematis dalam mendampingi (menfasilitasi) individu, kelompok, maupun komunitas dalam 
mengatasi permasalahan dan menyesuaikan diri dengan kesulitan hidup yang dialami sehingga mereka dapat mengatasi permasalahan tersebut untuk mencapai perubahan hidup ke arah yang lebih baik (Purwanto, 2019). Ketiga metode tersebut dapat memberikan pengalaman nyata dan secara langsung dapat dirasakan oleh masyarakat, sehingga dapat memicu kemampuan masyarakat dalam mengembangkan kemampuannya. Selain ketiga metode, untuk mengukur keberhasilan program dilakukan dengan teknik kuesioner. Teknik kuesioner adalah. suatu alat untuk mengumpulkan pengumpul informasi dengan cara memberikan sejumlah pertanyaan tertulis untuk dijawab pula secara tertulis juga oleh responden (Damayanti, 2014; Isti Pujihastuti, 2010). Penggunaan kuesioner ini membantu evaluasi pelaksanaan program dan memudahkan pengukuran tingkat keberhasilan program.

\section{HASIL DAN PEMBAHASAN}

\section{Hasil}

Dusun Munti Gunung memiliki potensi pariwisata yang sangat besar jika dapat dimanfaatkan dan dikelola dengan baik. Dengan adanya potensi tersebut, maka tim PHP2D Himpunan Mahasiswa Jurusan Pendidikan Dasar Universitas Pendidikan Ganesha memberikan beberapa kegiatan yang sudah dilaksanakan Tim PHP2D bersama masyarakat Dusun Munti Gunung, Desa Tianyar Barat, Kecamatan Kubu, Karangasem. Kegiatankegiatan yang dimaksud seperti 1) Membentuk community social entrepreneurship berbasis industri keatif dan desa wisata untuk mewadahi masyarakat miskin di Dusun Munti Gunung. Kegiatan ini dilakukan menggunakan metode Focus Group Discussion (FGD), dengan tujuan dapat menjadi wadah bagi masyarakat untuk meningkatkan kualitas diri dan mengembangkan mental kewirausahaan. Entrepreneurship adalah segala sesuatu yang berkaitan dengan sikap, tindakan dan proses yang dilakukan oleh para entrepreneur dalam merintis, menjalankan, dan mengembangkan usaha mereka (Paramita \& Erdiansyah, 2016). Entrepreneurship ini terbukti telah mampu mengatasi tingkat pengangguran melalui penciptaan lapangan pekerjaan oleh entrepreneur (Wijatno, 2009). Social entrepreneurship merupakan salah satu strategi atau kegiatan untuk memberdayakan masyarakat dalam rangka mendukung upaya pengentasan kemiskinan pedesaan (Yusriadi et al., 2020). Social entrepreneurship dianggap dapat menjadi salah satu alternatif dalam pemecahan masalah perekonomian sosial. Kegiatan social entrepreneurship jika dilihat dari program pelaksanaanya memiliki peran yang hampir sama dengan tujuan ekonomi sendiri dalam upaya peningkatan pertumbuhan dan kesejahteraan ekonomi (Nurfaqih \& Fahmi, 2018; Reindrawati, 2017). 2) Sosialisasi dan edukasi anggota community social entrepreneurship untuk meningkatkan kesadaran, motivasi, dan membentuk mental wirausaha masyarakat Munti. Kegiatan ini menggunakan metode sosialisasi. 3) Pelatihan pengemasan industri kreatif berbasis IPTEK. Kegiatan ini dilakukan dengan metode pelatihan dan pendampigan dengan tujuan memberikan keterampilan baru kepada masyarakat dalam melakukan pengembangan industri kreatif. 4) Pelatihan pemasaran industri kreatif yang dihasilkan oleh anggota community social entrepreneurship dengan menggunakan social media dan market place. Pemasaran melalui media sosial dapat digunakan sebagai alat yang berguna bagi para pelaku bisnis untuk mengenal lebih dalam dan memahami suatu hubungan serta memenuhi sesuatu yang dicari atau kebutuhan konsumen yang dibangun melalui media sosial secara efektif dan efisien (Adrian \& Mulyandi, 2021). Kegiatan ini dilakukan menggunakan metode pelatihan dan pendampingan dengan tujuan agar masyarakat dapat melakukan pemasaran industri kreatif secara online, sehingga cakupan pemasaran lebih luas dan dapat meningkatkan penjualan. 5) Pengembangan obyek wisata Munti Gunung's hiking track and Camp area, pembuatan paket wisata, pembuatan buku panduan bilingual. Kegiatan ini dilakukan menggunakan metode FGD dan pendampingan. Pengembangan objek wisata 
dilakukan secara terintegrasi dan masyarakat berperan penuh dalam pelaksanaan kegiatan ini. 6) Pelatihan pemasaran objek atau paket wisata. Kegiatan ini dilakukan menggunakan metode pelatihan dan pendampingan untuk meningkatkan kemampuan masyarakat dalam mengaplikasikan pengetahuan dan keterampilan yang diperolehnya. Kegiatan ini dilakukan di lapangan, baik di tempat kerja maupun di masyarakat. 7) Membangun hubungan kerjasama dengan pihak-pihak terkait. Membangun hubungan kerja sama dengan berbagai pihak dilakukan untuk membantu pengembangan wisata dan memperkenalkan wisata serta industri lebih luas. Membangun hubungan kerja sama merupakan hal yang sangat penting. Kerja sama tim merupakan suatu kemampuan untuk bekerja bersama dengan tujuan mengarahkan dan mendorong para individu ataupun kelompok menuju dan meraih tujuan secara bersamasama (Lasmi et al., 2022).

Berdasarkan kegiatan yang telah dilakukan oleh TIM PHP2D HMJ Pendas diharapkan masyarakat Munti Gunung dapat mengembangkan pariwisata di Munti Gunung. Di sampin itu, kegiatan ini membantu mengetahui provinsi yang memiliki pariwisata potensial di Indonesia, sehingga pengembangan wilayah di Indonesia agar lebih efektif dan efisien meningkatkan perekonomian (Basorudin et al., 2021). Dengan adan adanya sosialisasi dan edukasi anggota community social entrepreneurship, pembangunan pariwisata Bali dapat mengembangkan dan mendayagunakan berbagai potensi pariwisata daerah dan meningkatkan peran serta masyarakat (Andini \& Pujaastawa, 2018) dan sejalan dengan tujuan pembangunan desa sesuai pasal 78 adalah meningkatkan kesejahteraan masyarakat desa dan kualitas hidup manusia serta penanggulangan kemiskinan melalui pemenuhan kebutuhan dasar, pembangunan sarana dan prasarana desa, pengembangan potensi ekonomi lokal (Herry, 2015). Selain itu, dukungan pengemasan industri kreatif berbasis IPTEK dilakukan pendampingan proses promosi untuk produk serta pendampingan pada strategi pemasaran produk dapat menghasilkan produk dengan kualitas yang dapat diminati setiap konsumen (Indrihastuti et al., 2019). Dalam pengembangan wisata, yaitu pengembangan obyek wisata Munti Gunung's hiking track and Camp Area, pembuatan paket wisata, pembuatan buku panduan bilingual tentu sangat perlu partisipasi masyarakat Munti Gunung. Partisipasi masyarakat merupakan prasyarat penting dalam pelaksanaan pembangunan. Pembangunan yang tidak melibatkan masyarakat akan cenderung memarginalkan masyarakat itu sendiri (Sidiq \& Resnawaty, 2017). Selanjutnya, dilakukan pelatihan pemasaran. Strategi pemasaran berbasis teknologi dapat menjadi kekuatan utama mendongkrak penjualan produk-produk UMKM (Werdani et al., 2020).

\section{SIMPULAN DAN SARAN}

Permasalahan warga Dusun Munti Gunung salah satunya adalah perekonomian warga yang masih ada terbilang rendah. Potensi alam yang dimiliki Dusun Munti Gunung seharusnya bisa meningkatkan perekonomian masyarakat. Namun, masyarakat di sana belum dapat mengelola potensi yang ada secara maksimal. Kurangnya pengetahuan dan keterampilan mengakibatkan masyarakat Munti Gunung tidak memiliki banyak opsi pekerjaan. Masyarakat miskin di Munti Gunung masih belum mampu mengoptimalkan potensi kekayaan alam menjadi industri kreatif untuk menunjang sektor pariwisata atau kurangnya sentuhan IPTEK . Potensi keindahan alam yang terdapat di Munti Gunung masih belum dieksplorasi dan dikembangkan secara maksimal. Kegiatan ini menghasilkan luaran berupa terbentuknya community social entrepreneurship berbasis industri kreatif dan desa wisata untuk mewadahi masyarakat miskin di Dusun Munti Gunung. Hasil pengabdian kepada masyarakat ini diharapkan dapat mengatasi segala permasalahan kemiskinan yang ada di Dusun Munti Gunung, Desa Tianyar Barat. 


\section{DAFTAR RUJUKAN}

Adrian, D., \& Mulyandi, R. (2021). Manfaat Pemasaran Media Sosial pada Pembentukan Brand Awareness Toko Online. Jurnal Indonesia Sosial Sains, 2(2), 215-222. http://jiss.publikasiindonesia.id/index.php/jiss/article/view/195.

Andini, N. D., \& Pujaastawa, I. B. G. (2018). Peran Serta Elit Desa dalam Pengembangan Pariwisata di Desa Cempaga Kecamatan Banjar Kabupaten Buleleng Bali. Jurnal Humanis, 22(1), $87-95$. https://ojs.unud.ac.id/index.php/sastra/article/download/38279/23222.

Astuti, P. A. S., Muliawan, P., Sawitri, \& Septarini, N. W. (2010). Status Kesehatan Ibu di Dusun Munti Gunung, Karangasem, Bali. Jurnal Ilmu Kesehatan Masyarakat, 1(3). https://ejournal.fkm.unsri.ac.id/index.php/jikm/article/view/46.

Basorudin, M., Afifah, N., Rizqi, A., Yusuf, M., Humairo, N., \& SN, L. M. (2021). Analisis Location Quotient dan Shift Share Sektor Pariwisata sebagai Indikator Leading Sector di Indonesia. ECOBISMA(Jurnal Ekonomi, Bisnis Dan Manajemen), 8(1), 89-101.

Citra, I. P. A., \& Sarmita, I. M. (2019). Pemetaan Potensi Wisata untuk Pengembangan Desa Wisata Munti Gunung di Desa Tianyar Barat. Jurnal Widya Laksana, 8(1), 85-90. https://ejournal.undiksha.ac.id/index.php/JPKM/article/view/16606.

Damayanti, D. (2014). Sihapes (Sistem Informasi Hasil Penilaian Siswa) bagi Sekolah Menengah Pertama di SMP Negeri 7 Semarang. Edu Komputika Journal, 1(2), 52-62. https://doi.org/10.15294/edukomputika.v1i2.7803.

Fitriani, E., \& Azhar, A. (2019). Layanan Informasi Berbasis Focus Group Discussion (FGD) dalam Meningkatkan Kepercayaan Diri Siswa. Analitika: Jurnal Magister Psikologi UMA, 11(2), 82. https://doi.org/10.31289/analitika.v11i2.2552.

Hadinata, R. (2015). Analisis Metode Pelatihan dan Pengembangan Sumber Daya Manusia di Cv X. Agora, 3(2), 475-478. http://publication.petra.ac.id/index.php/manajemenbisnis/article/view/3680.

Hamda, N. (2014). Masyarakat dan Sosialisasi. Ittihad, 12(22), 107-115. http://sharenexchange.blogspot.com/2010/02/sosialisasi-masyarakat_8061.

Herdiana, D. (2018). Sosialisasi Kebijakan Publik: Pengertian dan Konsep Dasar. Jurnal Ilmiah Wawasan Insan Akademik, I(3), 13-26. http://www.stiacimahi.ac.id/?page_id=1181\%0Ahttps://www.researchgate.net/publica tion/337485273_Sosialisasi_Kebijakan_Publik_Pengertian_dan_Konsep_Dasar.

Herry, A. (2015). Kesiapan Desa Menghadapi Implementasi Undang-Undang Desa (Tinjauan Desentralisasi Fiskal dan Peningkatan Potensi Desa). CIVIS, $5(1)$. http://journal.upgris.ac.id/index.php/civis/article/view/634.

Indrihastuti, P., Arvianti, E. Y., \& Dewi Novitawati, R. A. (2019). Teknik Design Labeling Pengembangan Model Kemasan Keripik Salak Pondoh oleh Wanita Tani Srikandi dan Karya Bhakti. JAST: Jurnal Aplikasi Sains Dan Teknologi, 3(2), 115. https://core.ac.uk/download/pdf/270210034.pdf.

Lasmi, A., Bayhaqi, H., \& Suhairi. (2022). Membangun Kerjasama Tim yang Efekti dalam Organisasi Aida. Dawatima Journal of Communication and Islamic Broadcasting, 2(1), 35-45. https://doi.org/10.47476/dawatuna.v2i1.509.

Muhlis, M., Soepeno, \& Rinda, R. T. K. (2018). Pelatihan dan Pemotivasian terhadap Pengembangan Karir Karyawan. Manager: Jurnal Ilmu Manajemen, 1(1), 45. https://doi.org/10.32832/manager.v1i1.1437.

Nurfaqih, M. I., \& Fahmi, R. A. (2018). Social Entrepreneurship (Kewirausahaan Sosial) dalam Perspektif Ekonomi Islam. https://dspace.uii.ac.id/handle/123456789/9780.

Paramita, S., \& Erdiansyah, R. (2016). Entrepreneurship dan New Media pada Generasi Muda. Kaji Tindak: Jurnal Pemberdayaan Masyarakat, 3(1), 1-8.

Pujihastuti, I. (2010). Prinsip Penulisan Kuesioner Penelitian. CEFARS: Jurnal Agribisnis 
$\begin{array}{lcr}\text { dan } & \text { Pengembangan } & \text { Wilayah, 2(1), } \\ \text { https://jurnal.unismabekasi.ac.id/index.php/cefars/article/view/63. }\end{array}$

Purwanto, I. (2019). Upaya Meningkatkan Kompetensi Guru Sasaran dalam Penyusunan RPP yang Baik dan Benar Sesuai Kurikulum 2013 (Kurtilas) Semester Satu Tahun Pelajaran 2018/2019 Di SMP Negeri 9 Mataram Melalui Pendampingan Berbasis MGMP. JISIP, $3(1)$. http://ejournal.mandalanursa.org/index.php/JISIP/article/view/620.

Putri, N. R., \& Ratnasari, S. L. (2019). Pengaruh Tingkat Pendidikan, Pelatihan, dan Pengembangan Karir terhadap Kinerja Karyawan PT. Asuransi Takaful Batam. Jurnal Akuntansi, Ekonomi Dan Managemen Bisnis, 7(1), 48-55. https://doi.org/10.30871/jaemb.v7i1.1083.

Reindrawati, D. Y. (2017). Tantangan dalam Implementasi Social Entrepreneurship Pariwisata di Pulau Madura. Masyarakat, Kebudayaan Dan Politik, 30(3), 215-228. https://www.e-journal.unair.ac.id/MKP/article/view/3221.

Romi, S., \& Umiyati, E. (2018). Pengaruh Pertumbuhan Ekonomi dan Upah Minimum terhadap Kemiskinan di Kota Jambi. E-Jurnal Perspektif Ekonomi Dan Pembangunan Daerah, 7(1), 1-7. https://online-journal.unja.ac.id/pdpd/article/view/4439.

Rosyadi, I. (2017). Identifikasi Faktor Penyebab Kemiskinan di Pedesaan dalam Perspektif Struktural. URECOL, 499-512. http://journal.unimma.ac.id/index.php/urecol/article/view/1478.

Santoso, B. (2010). Skema dan Mekanisme Pelatihan. Yayasan Terumbu Karang Indonesia (TERANGI).

Sidiq, A. J., \& Resnawaty, R. (2017). Pengembangan Desa Wisata Berbasis Partisipasi Masyarakat Lokal di Desa Wisata Linggarjati Kuningan, Jawa Barat. Prosiding Penelitian Dan Pengabdian Kepada Masyarakat, 4(1), 38-44. http://journal.unpad.ac.id/prosiding/article/view/14208.

Swadayaningsih, M. (2020). (FGD) Meningkatkan Kemampuan Guru dalam Memanfaatkan Lingkungan Sekolah sebagai Sumber Belajar di SD. Jurnal Ilmiah Sekolah Dasar, 4(1), 74. https://doi.org/10.23887/jisd.v4i1.24102.

Waluyati, M. (2020). Penerapan Fokus Group Discussian (FGD) untuk Meningkatkan Kemampuan Memanfaatkan Lingkungan sebagai Sumber Belajar. Jurnal Edutech Undiksha, 8(1), 80. https://doi.org/10.23887/jeu.v8i1.27089.

Werdani, R. E., Kurniawati, N. I., Sukoco, J. B., Windriya, A., \& Iskandar, D. (2020). Pelatihan Pemasaran Produk Homemade melalui Sosial Media. JPPM (Jurnal Pengabdian Dan Pemberdayaan Masyarakat), 4(1), 1-5. http://www.jurnalnasional.ump.ac.id/index.php/JPPM/article/view/4655.

Wijatno, S. (2009). Pengantar Entrepreneurship. Grasindo.

Yasa, N. L. S., Sudiatmaka, K., \& Adnyani, N. K. S. (2014). Peranan Desa Adat dalam Menanggulangi Gepeng Asal Dusun Muntigunung, Desa Tianyar Barat, Kecamatan Kubu, Kabupaten Karangsem. Jurnal Pendidkan Kewarganegaraan, 2(2), 1-13. https://ejournal.undiksha.ac.id/index.php/JJPP/article/view/1130.

Yusriadi, Y., bin Tahir, S. Z., Awaluddin, M., \& Misnawati, M. (2020). Pengentasan Kemiskinan melalui Socialpreneur. Wikrama Parahita: Jurnal Pengabdian Masyarakat, $\quad 4(2), \quad 115-120 . \quad$ https://ejurnal.lppmunsera.org/index.php/parahita/article/view/2529. 